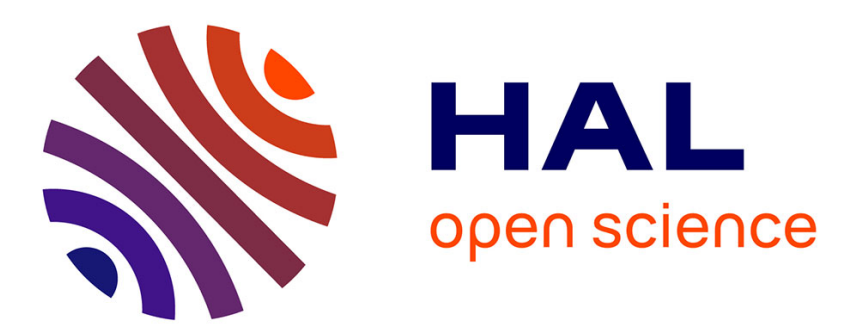

\title{
An Assessment of the Surface Properties of Milled Attapulgite Using Inverse Gas Chromatography
}

\author{
L. Boudriche, B. Hamdi, Z. Kessaissia, Rachel Calvet, Alain Chamayou, John
}

A. Dodds, H. Balard

\section{- To cite this version:}

L. Boudriche, B. Hamdi, Z. Kessaissia, Rachel Calvet, Alain Chamayou, et al.. An Assessment of the Surface Properties of Milled Attapulgite Using Inverse Gas Chromatography. Clays and Clay Minerals, 2010, 58 (2), pp.143-153. 10.1346/CCMN.2010.0580201 . hal-01667190

\section{HAL Id: hal-01667190 https://hal.science/hal-01667190}

Submitted on 7 Nov 2018

HAL is a multi-disciplinary open access archive for the deposit and dissemination of scientific research documents, whether they are published or not. The documents may come from teaching and research institutions in France or abroad, or from public or private research centers.
L'archive ouverte pluridisciplinaire HAL, est destinée au dépôt et à la diffusion de documents scientifiques de niveau recherche, publiés ou non, émanant des établissements d'enseignement et de recherche français ou étrangers, des laboratoires publics ou privés. 


\title{
AN ASSESSMENT OF THE SURFACE PROPERTIES OF MILLED ATTAPULGITE USING INVERSE GAS CHROMATOGRAPHY
}

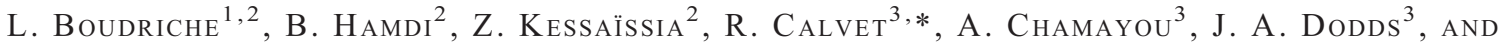 \\ H. BALARD ${ }^{4}$ \\ ${ }^{1}$ Centre de Recherche Scientifique et Technique en Analyse Physico-Chimique (C.R.A.P.C.), BP 248, Alger Rp, 16004, Alger, \\ Algeria \\ ${ }^{2}$ Laboratiore d'Etude Physico-Chimique des Matériaux et Application à l'Environnement, Faculté de Chimie, USTHB, BP 32 El \\ Alia, Bab Ezzouar, 16111, Alger, Algeria \\ ${ }^{3}$ Ecole des Mines d'Albi Carmaux, Campus Jarlard, 81013 Albi CEDEX 09, France \\ ${ }^{4}$ Laboratoire de Chimie Physique, ENSISA-W, 11, rue Werner, 68093 Mulhouse CEDEX, France
}

\begin{abstract}
The most common means of reducing the particle size of solids is by grinding, a process which can affect the surface properties and the behavior of the solid in later stages (granulation, compaction, etc.), and which can influence the end-use properties of the final product. Inverse gas chromatography (IGC) measurements were used here to evaluate the influence of grinding, in a ball mill, on attapulgite. The milling experiments were performed in dry media for various periods. After 30 min of grinding, significant decreases in the particle size and specific surface areas were observed when calculated using different probes. No noticeable variation in the surface properties was observed by IGC either at infinite dilution or at finite concentration, however. In particular, the distribution functions of the adsorption energies (DFAE), giving information about the surface heterogeneity for both an apolar probe (octane) and a polar probe (isopropanol), remained unchanged, regardless of the grinding time. The stability of the surface energy with respect to the grinding process was seen to be related to the particular fibrous structure of the attapulgite clay.
\end{abstract}

Key Words-Adsorption Energy Distribution Functions, Attapulgite, Grinding, Inverse Gas Chromatography, Palygorskite, Surface Properties.

\section{INTRODUCTION}

Grinding processes are important industrial operations, currently used to reduce the particle sizes of various materials, and in particular to produce powders from the rocks extracted from mines or quarries, as is the case for attapulgite.

Different studies have been carried out on the effect of grinding on clay minerals, such as the effect of micronization on the crystalline structure of kaolinite (Suraj et al., 1997). Ball milling was found to be a relatively low-impact process where the structural changes in the mineral were minimal, whereas use of an oscillatory mill could lead to an almost complete destruction of the clay structure, including amorphization. Using the ball mill, a greater effect was observed (by X-ray diffraction, XRD) for particles after dry grinding than after wet grinding. A study of montmorillonite (Hrachova et al., 2007) revealed a complete breakdown of its layers after $3 \mathrm{~h}$ of dry grinding in a vibration mill. Papirer et al. (1986) monitored the surface free-energy characteristics of mica (muscovite) samples after grinding in water and organic solvents

* E-mail address of corresponding author: rachel.calvet@mines-albi.fr (methanol and toluene) and found that in methanol the dispersive component of the surface energy $\left(\gamma_{\mathrm{s}}^{d}\right)$ increased significantly after very short grinding times. The same observation was made regarding the evolution of the specific surface area. The increase in these two parameters could be related to the creation of a lateral surface area of mica flakes. On the other hand, in toluene $\gamma_{\mathrm{s}}^{d}$ decreased after prolonged grinding as a consequence of particle agglomeration.

Grinding generally induces a fragmentation of the original particles, creating new surfaces which may exhibit new surface properties, in particular, under the effect of the mechanical stresses imposed by the grinding tool. Understanding the effects of a grinding process is, therefore, important in order to characterize the ground solids, from the point of view of their surface-interaction potential. Analytical methods based on the adsorption phenomenon are particularly well suited to such a characterization, among them inverse gas chromatography, which has many advantages in providing information on the interactivity, morphology, and heterogeneity of the solid surface.

The aim of the present work was to use these analytical techniques on a crystalline hydrated magnesium aluminum silicate (Murray, 2000; Galán, 1996) with a fibrous morphology, to see if its surface properties changed when it was subjected to a grinding process. Attapulgite, or palygorskite, is a fibrous $\mathrm{Mg}$-clay 
generally containing large amounts of $\mathrm{Al}(\mathrm{III})$ and $\mathrm{Fe}(\mathrm{III})$ cations. Their precise crystal chemistries (site occupancy, distribution of cations, di- or trioctahedral character) have been the subject of many studies (Galán and Carretero, 1999; Chahi et al., 2002; Suarez and García-Romero, 2006). Attapulgite belongs to the class of 2:1 phyllosilicates (García-Romero et al., 2004) in which the sheets of silica tetrahedra are periodically inverted with respect to the tetrahedral bases. Consequently, the octahedral sheets are periodically interrupted and terminal cations must complete their coordination sphere with water molecules. The crystal structure was proposed for the first time by Bradley in 1940 (Figure 1). Because of this inversion, the structure of attapulgite exhibits a fibrous habit.

\section{THEORETICAL CONSIDERATIONS}

\section{$I G C$ theory}

Unlike analytical gas chromatography (GC) where a known stationary phase is used to separate and identify the unknown injected product, Inverse Gas Chromatography (IGC) uses well characterized molecules, known as 'probes,' to determine the interaction capacities of the unknown material packed into the column. The technique can be carried out in two ways: at infinite dilution (IGC-ID) (Balard et al., 2000) and at finite concentration (IGC-FC) (Conder and Young, 1979; Balard, 1997).

Inverse gas chromatography at infinite dilution (IGC-ID)

IGC-ID consists of the injection of minute amounts of vapor of the probe molecules, the properties (length, polarity, acidity) of which are known at low concentrations in such a way that the interactions between adsorbed molecules can be considered as negligible.

Depending on the chemical nature of the probe molecule, IGC-ID provides information about several parameters: (1) The dispersive component of the surface energy $\left(\gamma_{\mathrm{s}}^{d}\right)$ is obtained by injections of linear alkanes. The parameter indicates the ability of the solid surface to have non-specific interactions with probe molecules (Dorris and Gray, 1979). (2) The nanomorphological index $I_{\mathrm{M}}\left(\chi_{\mathrm{t}}\right)$ can be calculated by injections of branched or cyclic alkanes and the value gives information about the regularity of the solid surface at the molecular scale (Brendlé and Papirer, 1997). (3) The specific component of the surface energy $\left(I_{\mathrm{sp}}\right)$ can be determined by injections of polar probes, and gives information about polar interactions (Balard et al., 2000). The principles, advantages, and limitations of IGC-ID were reviewed by Balard (2000) and will not be discussed further here.

\section{Inverse gas chromatography at finite concentration $(I G C-F C)$}

In IGC-FC, a few $\mu \mathrm{L}$ of liquid probe are injected into a column containing the solid to be analyzed, in order to provide a covering that is approximately mono-layered on the surface of the solid. A highly asymmetric chromatographic peak results when ideal, nonlinear conditions are fulfilled. Due to the presence of very high-energy adsorption sites, a non-negligible part of the injected probe is usually not eluted and the signal returns to the initial base line. In order to assess this irreversibly adsorbed amount, the temperature of the chromatograph oven is increased to conditioning temperature, leading to the appearance of a secondary small peak. This gives an assessment of the irreversible part of the adsorption phenomena from the ratio of the area of the thermodesorption peak with respect to the total area of the chromatogram, allowing an irreversibility index $\left(I_{\text {irr }}\right)$, as previously defined (Balard et al., 2008), to be computed according to equation 1 :

$$
I_{\mathrm{irr}}=S_{\mathrm{th}} /\left(S_{\mathrm{rv}}+S_{\mathrm{th}}\right)
$$

where $S_{\mathrm{rv}}$ is the surface of the main chromatographic peak and $S_{\text {th }}$ is the surface corresponding to the thermodesorption peak.

By applying 'the elution characteristic point method' (ECP) to the reversible isothermal part of the experimental chromatogram, the desorption isotherm of the probe molecule can be obtained from a single chromato-
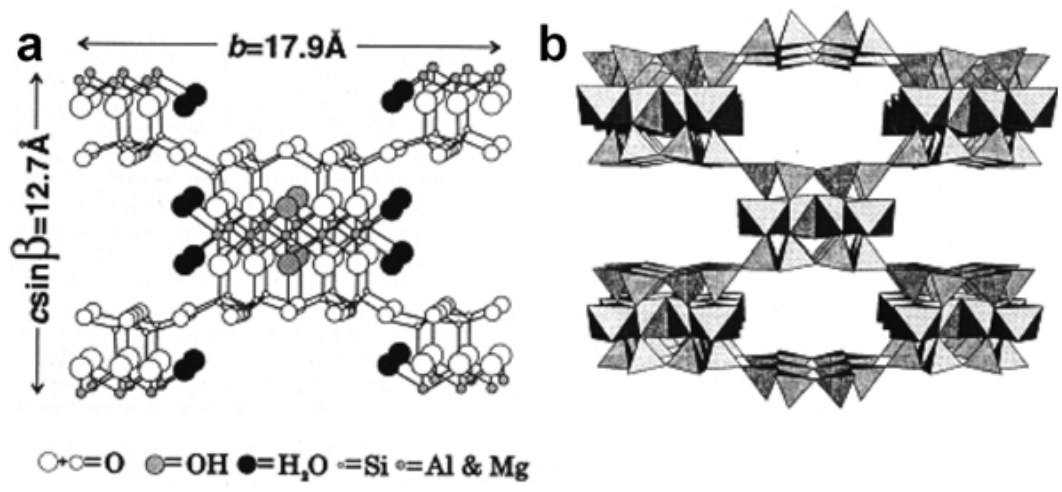

Figure 1. (a) Crystal structure of attapulgite (Bradley, 1940) and (b) its polyhedral representation (Mckeown et al., 2002). 
graphic peak (Conder and Young, 1979). The first derivative of the isotherm is related directly to the net retention time of each point of the diffuse front of the chromatogram by equation 2 :

$$
\left(\frac{\partial N}{\partial P}\right)_{\mathrm{L}, \mathrm{t}}=\frac{J D_{\mathrm{c}}\left(T-t_{0}\right)}{m \mathrm{R} T}
$$

where, for a given characteristic point, $N$ is the number of adsorbed probe molecules; $P$, the partial pressure of the probe at the output of the column (directly related to the height of the signal); $t_{\mathrm{r}}$, the retention time; $t_{0}$, the retention time of methane; $D_{\mathrm{C}}$, the corrected flow rate; $m$, the mass of the solid in the column; and $L$, the column length. $\mathrm{R}$ is the universal gas constant and $T$ the temperature. Integration of equation 2 provides the desorption isotherm which allows Henry's constant and the BET constants to be determined, as well as the specific surface area (Figure 2). The surface heterogeneity influences the shape of the desorption isotherm. Intuitively, the residence times of the adsorbed molecules depend on the energy of the adsorption site. Analysis of the shape of the isotherm therefore permits calculation of the distribution function of the adsorption energies

Distribution function of the adsorption energies (DFAE)

Estimation of the surface heterogeneity of a solid through the adsorption energy distribution function is generally based on a physical adsorption model which notes that the global isotherm may be considered to be the sum of local isotherms of adsorption on iso-energetic domains (patchwork model) (Balard, 1997; Rudzinski et al., 1982; Balard et al., 1998). The distribution function of the relative abundance of each type of domain having the same characteristic energy of interaction $(\varepsilon)$ is thus given by the following integral equation:

$$
N(T, P)=N \int_{\Omega} \theta(\varepsilon, T, P) \chi(\varepsilon) d \varepsilon
$$

where $N(T, P)$ is the number of molecules adsorbed at pressure $P$ and temperature $T$ of the measurement; $N_{0}$, the number of molecules corresponding to the formation of a monolayer; $\theta(\varepsilon, T, P)$, the local isotherm corresponding to adsorption sites having the same characteristic adsorption energy, $\varepsilon ; \chi(\varepsilon)$, the so-called distribution function of the adsorption energies (DFAE) describing the energies which exist at the gas-solid interface; and $\Omega$ the physical domain of the adsorption energy.

Solution of the integral in equation 3 , which is a convolution product, with Langmuir's isotherm as Kernel is not trivial because computing the DFAE from the isotherm data corresponds to a deconvolution operation. Different models have been applied, particularly the well known condensation approximation and the extended Rudzinski et al. method (Balard, 1997; Rudzinski et al., 1982). A method has also been developed allowing the lateral energy of interaction to be taken into account, while also delivering a DFCA corrected from this interaction so that a Langmuir local equation can be used (Balard et al., 2008). This approach, based on decomposition of the extrapolated DFCA into two components (homogeneous and heterogeneous), delivers an index of heterogeneity of the solid surface of interest for the probe used, which is equal to the ratio of the area of the homogeneous component $\left(A_{\mathrm{Hm}}\right)$ over the total area of the experimental DFCA $\left(A_{\mathrm{T}}\right)$, so that $I_{\text {hete }}$ is given by equation 4 :

$$
I_{\text {hete }}=\frac{A_{\mathrm{Hm}}}{A_{\mathrm{T}}}
$$

Starting from the DFCA corrected from the lateral energy of interaction, Rudzinski-Jagiello approximations can be computed up to $4^{\text {th }}$ order, designed as DFRJ,

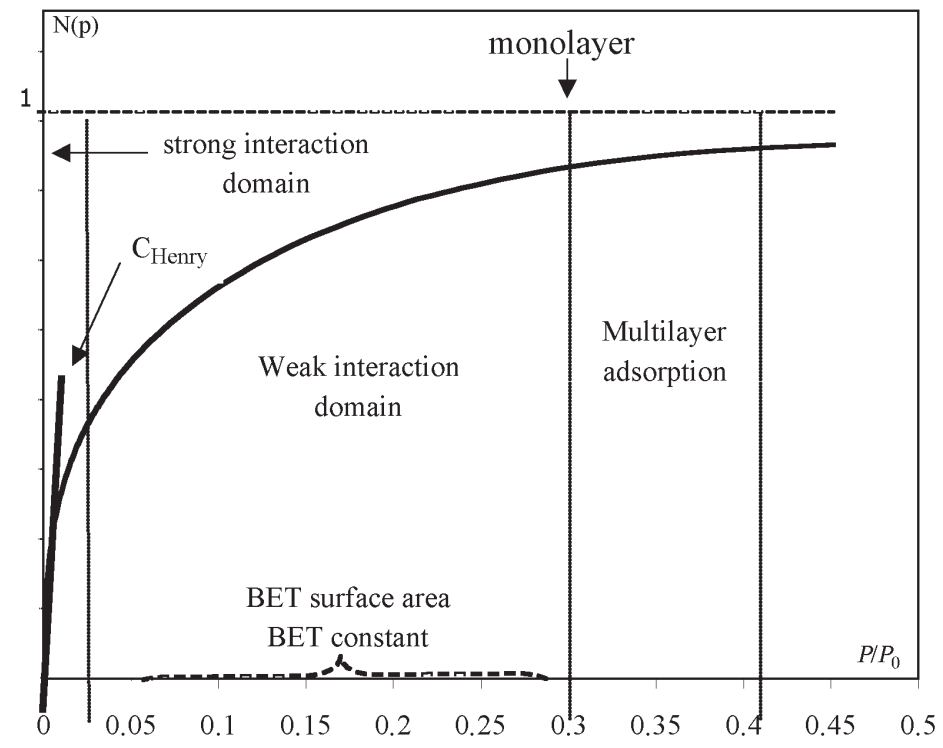

Figure 2. Exploitation of the desorption isotherm. 
using a computing method based on Fourier's transforms as described elsewhere (Balard, 1997).

\section{MATERIALS AND METHODS}

\section{Attapulgite}

The attapulgite used in this study came from the region of Ghoufi, near Biskra in the northeast of Algeria. The crude attapulgite was first coarsely crushed and sieved to obtain a $<1 \mathrm{~mm}$ size fraction allowing easier analysis, measurements, and treatments to be made in laboratory-scale processes.

\section{Grinding conditions}

Ball-milling experiments were carried out for different processing times $(15,30,60,120$, and $180 \mathrm{~min})$, with a MARNE 1 device supplied by the FAURE Equipment Company (Limoges, France). One-liter jars were filled with $1 \mathrm{~kg}$ of ceramic grinding media (balls with different diameters: $20 \%$ of $24 \mathrm{~mm}, 20 \%$ of $19 \mathrm{~mm}$, and $60 \%$ of $12 \mathrm{~mm}$ ). The rotation speed of the ball mill was fixed at $70 \mathrm{rpm}$. A volume of $200 \mathrm{~cm}^{3}$ of attapulgite powder was placed in the jars with the grinding media.

\section{Characterization of ground attapulgite}

After each grinding experiment, particle-size distribution measurements were performed by a laser diffraction method using a Malvern Mastersizer 2000 device, fed using a dry-way feeder with a dispersion pressure of 3.5 bar.

The specific surface areas, BET constants, and mesoand micro-pore volumes were determined using nitrogen adsorption at liquid nitrogen temperature (ASAP 2010, Micromeritics) by applying the BET, BJH, and HK methods, respectively.

Phase identification was performed on a Panalytical X'PERT Pro diffractometer (Philips) ( $\mathrm{CuK} \alpha$ radiation) with a step size of $0.017^{\circ}$ for $2 \theta$ angles ranging from $5^{\circ}$ to $80^{\circ}$. The $2 \theta$ values were compared with the JCPDS database. The particle morphology was investigated using a scanning electron microscope (Philips XL 30 model ESEM-FEG) operating at $3 \mathrm{kV}$. The elementary composition of attapulgite was established by X-ray Fluorescence (XRF) using a Philips MagiX model (Mulhouse, France).

\section{Inverse gas chromatography}

The IGC measurements were performed using two (commercial) GC devices (Agilent $7890 \mathrm{~A}$ and 6890), fitted with sensitive flame ionization detectors (FID). Helium was used as the carrier gas with a flow rate of $30 \mathrm{~mL} / \mathrm{min}$ measured with an electronic flowmeter (Flow 500-Agilent). The temperatures of the injector and detector were $130^{\circ} \mathrm{C}$ and $200^{\circ} \mathrm{C}$, respectively. The columns were filled with a mixture of attapulgite powder and glass beads, $90 \mathrm{~mm}$ in diameter, in order to avoid fitting leaks by reducing the pressure drop ( $<1$ bar) through the columns.
The IGC-ID study was performed with an oven temperature of $130^{\circ} \mathrm{C}$, using stainless steel columns $20 \mathrm{~cm}$ long and $0.6 \mathrm{~cm}$ in diameter. The columns were conditioned overnight at $150^{\circ} \mathrm{C}$. The probes used were linear alkanes (hexane C6, heptane C7, and octane C8) (Fluka); a branched alkane, 2,3,4-trimethylpentane (2,3,4-TMP) (Aldrich); a cyclic alkane, cycloctane (cyclo8) (Fluka); and polar probes (chloroform (Acros organics) and dichloromethane (Fisher)). All probes used were of GC purity.

For IGC-FC, the chromatographic columns were $10 \mathrm{~cm}$ long with a diameter of either $0.6 \mathrm{~cm}$ or $0.3 \mathrm{~cm}$. The conditioning temperature was $130^{\circ} \mathrm{C}$ and the analysis temperature depended on the probe used, according to the Conder (1979) criterion which stated that the contribution of probe vapor to the flow of carrier gas should not exceed $5 \%$ of the initial flow at the maximum of the chromatographic peak. Two probes were used in IGC-FC, octane (C8) at $53^{\circ} \mathrm{C}$ and isopropanol (IP) (Fluka) at $43^{\circ} \mathrm{C}$. The chromatograms were analysed using software created by Balard.

\section{RESULTS AND DISCUSSION}

\section{Before grinding}

Observation by SEM (Figure 3) revealed the fibrous structure of the attapulgite, which explains its large specific surface area of $\sim 125 \mathrm{~m}^{2} / \mathrm{g}$ and its significant adsorption capacity, which in turn explains its application in environmental remediation and in anti-diarrhoeal medications.

The reflections identified in the XRD pattern (Figure 4) indicated that the material consisted of attapulgite but also contained some significant amounts of dolomite $\left(\mathrm{CaMg}\left(\mathrm{CO}_{3}\right)_{2}\right)$ and ankerite $\left(\mathrm{Ca}(\mathrm{Fe}, \mathrm{Mg}, \mathrm{Mn})\left(\mathrm{CO}_{3}\right)_{2}\right)$. The elementary composition, established by XRF, was compared to that reported by Bradley (1940) (Table 1). The two attapulgite samples had similar compositions, and the differences could be attributed to the geological origins of the materials, one coming from Georgia and the other from Algeria.

\section{Influence of grinding}

Particle-size analysis. The first effect of the grinding process was to reduce the particle size of the solid. The values of the main characteristic diameters of the ground attapulgite samples were measured (Table 2). The particle diameters of the ground attapulgite decreased quickly during the first few minutes and reached a limit within $2 \mathrm{~h}$ of grinding, with a weak trend to reagglomeration for the longer processing times. The evolution of the particle-size distribution followed the grinding time (Figure 5).

Up to a $30 \mathrm{~min}$ grinding time, the particle-size distribution curves were bi-modal, exhibiting an increasing component centered around $30 \mu \mathrm{m}$, whereas the 


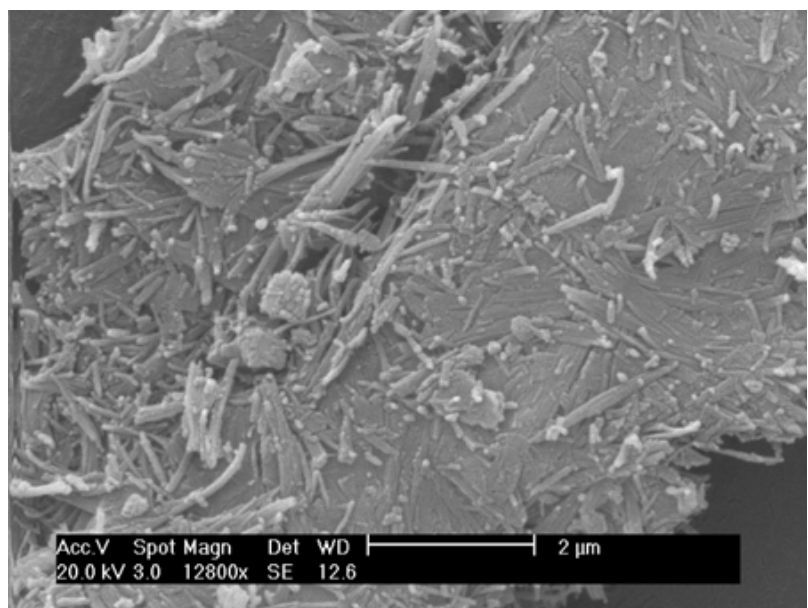

Figure 3. SEM image of attapulgite fibers.

coarse particle population decreased concomitantly. Beyond this critical grinding time, the distribution functions became mono-modal and independent of the grinding time, indicating that a limit had been reached in the grinding process.

BET surface analysis. To check whether this process influenced the specific surface area and the surface morphology of the attapulgite, the samples were submitted to BET surface analysis (Table 3). During the first hour of grinding, a decrease of $30 \%$ in the BET specific surface area was observed, with an increase occurring between 120 and $180 \mathrm{~min}$. The initial decrease, in apparent contradiction to particle-size reduction, could be explained by changes in the particle structure. Taking into account the measured particle size and the external specific surface area (calculated with the assumption of spherical particles), the BET specific surface area of attapulgite mainly results from an internal porosity and not from the particle size. According to this interpretation, after $2 \mathrm{~h}$ of grinding
Table 1. Chemical composition (XRF) of raw attapulgite.

\begin{tabular}{lcc}
\hline Elements (\%) & $\mathrm{A}$ & $\mathrm{B}$ \\
\hline $\mathrm{SiO}_{2}$ & 55.03 & 52.61 \\
$\mathrm{MgO}$ & 10.49 & 13.34 \\
$\mathrm{Al}_{2} \mathrm{O}_{3}$ & 10.24 & 10.67 \\
$\mathrm{CaO}$ & - & 9.55 \\
$\mathrm{Fe}_{2} \mathrm{O}_{3}$ & 3.53 & 4.66 \\
$\mathrm{~K}_{2} \mathrm{O}$ & 0.47 & 1.11 \\
\hline
\end{tabular}

(A) Chemical composition of attapulgite from Attapulgus (Georgia), freed of impurities (Bradley, 1940).

(B) Chemical analysis of the clay fraction used in the present study.

the increase in the BET specific surface area could be attributed to the appearance of a new internal porosity. The variations in the BET specific surface area agreed with the variations in the mesoporosity. A significant change in the BET constant was observed during the first $30 \mathrm{~min}$, indicating large changes in the surface interaction capacity. After this initial $30 \mathrm{~min}$, it became stable.

$X R D$ analysis. The grinding process in a ball mill for a period of $3 \mathrm{~h}$ did not influence the mineral composition, which remained constant within the resolution of XRD (Figure 4).

In order to gain a better insight into the surface properties of the attapulgite, the solid was examined using IGC analysis in infinite dilution (IGC-ID) and finite concentration (IGC-FC) conditions.

\section{Characterization of samples by IGC-ID}

The IGC parameters presented in Tables 4-6 include a relative standard deviation which takes into account the variability due to measurements with the chromatograph and to the heterogeneity of the powder.

The value of the dispersive component of the surface energy $\left(\gamma_{\mathrm{s}}^{d}\right)$ of attapulgite before grinding was found to be $164 \mathrm{~mJ} / \mathrm{m}^{2}$ (Table 4). Similar values of $\gamma_{\mathrm{s}}^{d}$ were

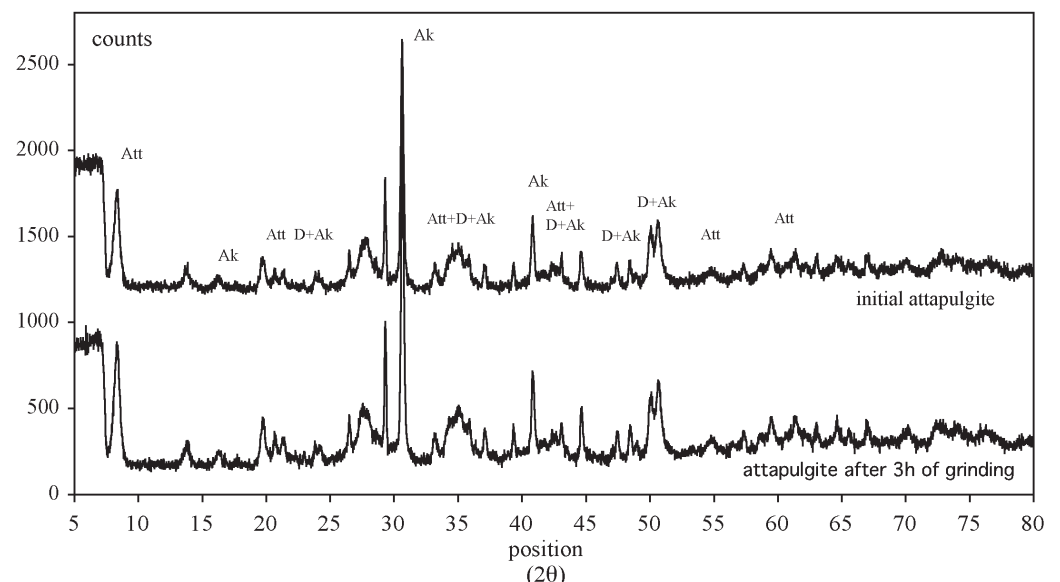

Figure 4. XRD patterns of attapulgite from Algeria (Att: attapulgite, Ak: ankerite, D: dolomite). 
Table 2. Variation with dry grinding time (in a ball mill) of the equivalent diameters of attapulgite particles, measured by laser light diffusion.

\begin{tabular}{lccr}
\hline Grinding time & $\begin{array}{c}d_{10} \\
(\mu \mathrm{m})\end{array}$ & $\begin{array}{c}d_{50} \\
(\mu \mathrm{m})\end{array}$ & $\begin{array}{c}d_{90} \\
(\mu \mathrm{m})\end{array}$ \\
\hline Initial & 31 & 510 & 1159 \\
$30 \mathrm{~min}$ & 8 & 37 & 185 \\
$60 \mathrm{~min}$ & 7 & 33 & 105 \\
$120 \mathrm{~min}$ & 7 & 24 & 50 \\
$180 \mathrm{~min}$ & 9 & 25 & 58 \\
& & & \\
\hline
\end{tabular}

observed by Saada et al. (1995) on two other clays, an illite and a kaolinite, which those authors attributed to the insertion of the n-alkane probes into the slot-like insertion sites present on the lateral surfaces of the crystals, corresponding to a greater force field than that resulting from a simple adsorption on a flat basal layer. In the present study, the probe was assumed to be inserted into the fibrous channels of the attapulgite or into structure defects between fibers.

The $\gamma_{\mathrm{s}}^{d}$ values measured on initial and ground attapulgite samples were compared (Table 4). Taking into account the relative standard deviation (4\%), the values of $\gamma_{\mathrm{s}}^{d}$ decreased slightly when the grinding time increased. The reduction by mechanical stress of some structural defects of the attapulgite crystal, which are able to receive the linear alkane probes, may be responsible.

To support this hypothesis, the adsorption behaviors of cyclic alkane probes were examined. The $I_{M}\left(\chi_{t}\right)$ parameters were measured on initial and ground
Table 3. Variation with dry grinding time (in a ball mill) of the specific surface area $\left(S_{\mathrm{BET}}\right)$, BET constant $\left(C_{\mathrm{BET}}\right)$, mesopore $\left(V_{\text {meso }}\right)$ volume, and micropore $\left(V_{\text {micro }}\right)$ volume of ground attapulgite samples, determined by nitrogen adsorption at $77 \mathrm{~K}$.

\begin{tabular}{lrccc}
\hline Grinding time & $\begin{array}{c}S_{\mathrm{BET}} \\
\left(\mathrm{m}^{2} / \mathrm{g}\right) \\
\pm 0.3\end{array}$ & $C_{\mathrm{BET}}$ & $\begin{array}{c}V_{\text {meso }} \\
\left(\mathrm{cm}^{3} / \mathrm{g}\right)\end{array}$ & $\begin{array}{c}V_{\text {micro }} \\
\left(\mathrm{cm}^{3} / \mathrm{g}\right)\end{array}$ \\
\hline Initial & 125.2 & 437 & 0.30 & 0.05 \\
$30 \mathrm{~min}$ & 99.3 & 187 & 0.31 & 0.04 \\
$60 \mathrm{~min}$ & 85.6 & 187 & 0.24 & - \\
$120 \mathrm{~min}$ & 85.8 & 209 & 0.24 & - \\
$180 \mathrm{~min}$ & 100.3 & 182 & 0.34 & 0.04 \\
\hline
\end{tabular}

attapulgite samples (Table 4$)$. The $I_{\mathrm{M}}\left(\chi_{\mathrm{t}}\right)$ parameters did not change significantly with grinding time, demonstrating that the surface morphology was not significantly affected by the grinding process.

By injecting acidic probes, such as chloroform and dichloromethane, the basic character of the attapulgite surface was assessed. The corresponding specific interaction parameters, $I_{\mathrm{sp}}$, were also evaluated (Table 4 ). Again no significant change in these parameters was observed with grinding time. One should note, however, that the measured values of the $I_{\mathrm{sp}}$ of attapulgite were greater than those determined by Saada (1995), Saada et al. (1995), and Aouadj (1997) on illite, kaolinite, and muscovite samples. Several other basic probes, such as dioxan, THF, ether, and pyridine were injected, but due to their strong interaction with the acidic hydroxyl groups on the attapulgite surface, they could not be

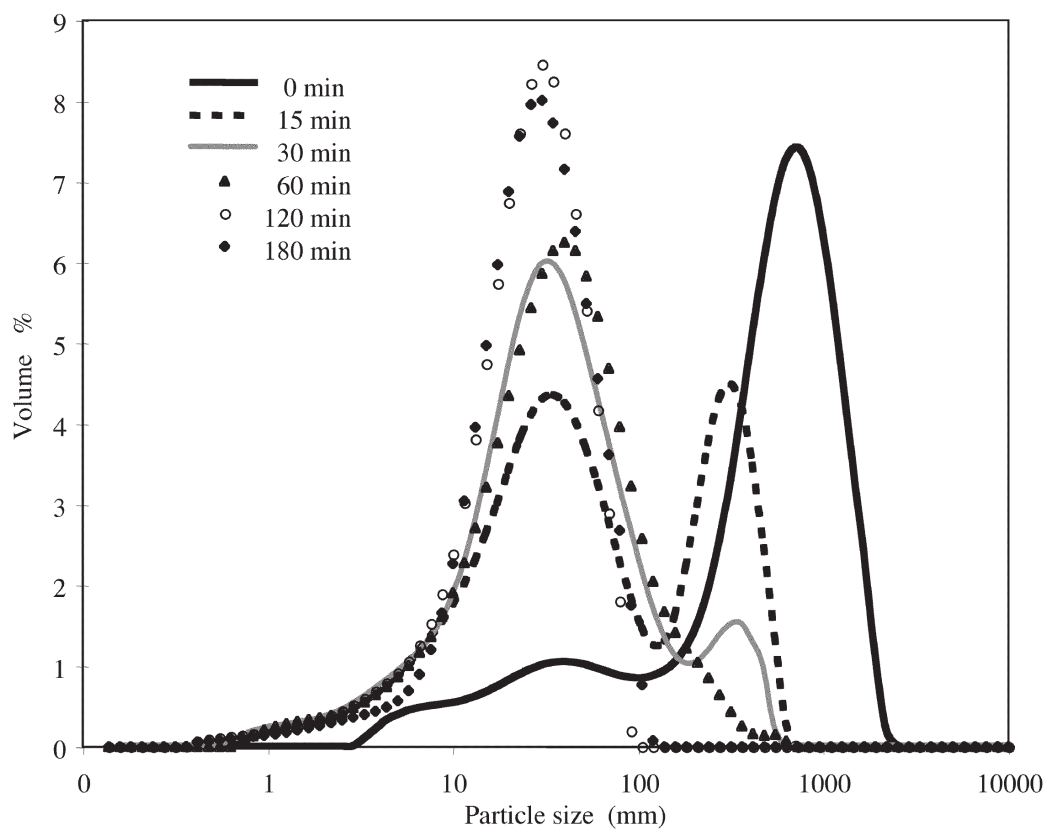

Figure 5. Evolution of the particle-size distributions of ground attapulgite samples, with increasing grinding times. 
Table 4. Variation with dry grinding time (in a ball mill) of the surface energy dispersive component $\left(\gamma_{\mathrm{s}}^{d}\right)$, of the nanomorphological index $\left(I_{\mathrm{M}}\right)$, and of the specific parameter $\left(I_{\mathrm{sp}}\right)$ values of attapulgite samples, determined by IGC-ID at $130^{\circ} \mathrm{C}$.

\begin{tabular}{|c|c|c|c|c|c|}
\hline \multirow[b]{2}{*}{ Grinding time } & \multirow{2}{*}{$\begin{array}{c}\gamma_{\mathrm{s}}^{d} \\
\left(\mathrm{~mJ} / \mathrm{m}^{2}\right) \pm 4 \%\end{array}$} & \multicolumn{2}{|c|}{$I_{\mathrm{M}}$} & \multicolumn{2}{|c|}{$I_{\mathrm{sp}}(\mathrm{kJ} / \mathrm{mole})$} \\
\hline & & $2,3,4-\mathrm{TMP} \pm 0.03 \%$ & Cyclo $8 \pm 0.01 \%$ & $\mathrm{CHCl}_{3} \pm 1 \%$ & $\mathrm{CH}_{2} \mathrm{Cl}_{2} \pm 1 \%$ \\
\hline Initial & 164 & 0.69 & 0.22 & 14 & 17 \\
\hline $30 \mathrm{~min}$ & 154 & 0.63 & 0.20 & 13 & 16 \\
\hline $60 \mathrm{~min}$ & 143 & 0.64 & 0.22 & 13 & 16 \\
\hline $120 \mathrm{~min}$ & 147 & 0.67 & 0.24 & 13 & 17 \\
\hline $180 \mathrm{~min}$ & 148 & 0.68 & 0.23 & 13 & 16 \\
\hline
\end{tabular}

eluted through the chromatographic column even at an oven temperature of $200^{\circ} \mathrm{C}$, testifying to the strongly acidic character of the attapulgite surface.

The results obtained by IGC-ID analysis, for grinding times up to $3 \mathrm{~h}$, were therefore in agreement with the evolution of the BET specific surface area. The decrease in internal porosity led to the disappearance of adsorption sites detected by the alkane probes, which was emphasized by the decrease in the dispersive component of the surface energy $\gamma_{\mathrm{s}}^{d}$.

The IGC-ID parameters are clearly related to the adsorption sites having the greatest energy of interaction (Balard et al., 2000). The IGC-FC analysis was then used to provide information on the whole surface of the samples under study.

\section{Characterization of samples by IGC-FC}

Determination of specific surface areas. The initial and ground samples were submitted to IGC-FC analysis using n-octane, an apolar probe, which is mainly sensitive to the surface morphology, and a polar probe, isopropanol, which is more sensitive to the surface functionality, especially the presence of silanol groups. The specific surface areas and the corresponding BET constants were measured by IGC-FC with the aforementioned probes on initial and milled attapulgite samples (Table 5). The specific surface areas varied in the same way regardless of the probe used: they decreased for the first hour of grinding and increased after $2 \mathrm{~h}$. The specific surface areas obtained using n-octane as the probe were close to those measured with nitrogen at $77 \mathrm{~K}$. On the contrary, isopropanol led to smaller specific surface area values, equal to $\sim 2 / 3$ of those obtained by nitrogen and n-octane. This discrepancy between the specific surface areas, which was not observed for fumed silica with a water probe (Brendle et al., 2005), could be attributed to the fact that the polar isopropanol probe was adsorbed only on the most polar part of the surface. It could also be explained by the more irreversible character of isopropanol adsorption compared to that of n-octane, as testified by their respective irreversible indexes $\left(I_{\text {irr }}\right)$ (Table 5). Of course, this irreversible adsorption contributed to the decrease in the measured specific surface areas computed from the reversible part of the adsorption phenomenon. On the other hand, the BET constant did not vary for n-octane $\left(C_{\mathrm{C} 8}\right)$ and only very weakly for isopropanol $\left(C_{\mathrm{IP}}\right)$.

Finally, the evolution of the specific surface areas, independent of the probe, showed a decrease in the internal porosity.

To corroborate these results, a study of the influence of the grinding process on the heterogeneous character of the studied solid was carried out by determining the distribution functions of the adsorption energies of both n-octane and isopropanol probes.

Study of surface heterogeneity. As described in the theoretical section above, the asymmetry of the distribution function of the adsorption energies (DFAE) can describe the surface heterogeneity by means of an index of heterogeneity $\left(I_{\text {hete }}\right)$. The values were determined for

Table 5. Comparison of specific surface area $\left(S_{\mathrm{C} 8}, S_{\mathrm{IP}}\right)$, BET constant $\left(C_{\mathrm{C} 8}, C_{\mathrm{IP}}\right)$, and heterogeneity $\left(I_{\text {hete }}\right)$ and irreversibility $\left(I_{\mathrm{irr}}\right)$ index values, measured by IGC-FC for n-octane and isopropanol probes, on attapulgite samples and for different grinding times.

\begin{tabular}{|c|c|c|c|c|c|c|c|}
\hline $\begin{array}{l}\text { Grinding time } \\
\text { (min) }\end{array}$ & $\begin{array}{c}\mathrm{N}_{2} \\
S_{\text {BET }}\left(\mathrm{m}^{2} / \mathrm{g}\right) \\
\quad \pm 0.3\end{array}$ & $\underset{\left(\mathrm{m}^{2} / \mathrm{g}\right) \pm 2.8}{S_{\mathrm{C} 8}}$ & $\begin{array}{c}\text { n-octane } \\
C_{\mathrm{C} 8}\end{array}$ & $\begin{array}{c}I_{\text {irr }} \\
(\%) \pm 0.2\end{array}$ & $\begin{array}{c}S_{\mathrm{IP}} \\
\left(\mathrm{m}^{2} / \mathrm{g}\right) \pm 4.0\end{array}$ & $\begin{array}{l}\text { propanol } \\
C_{\mathrm{IP}}\end{array}$ & $\begin{array}{c}I_{\text {irr }} \\
(\%) \pm 0.6\end{array}$ \\
\hline 0 & 125.2 & 114.5 & 9 & 0.1 & 70.9 & 22 & 8.3 \\
\hline 30 & 99.3 & 88.9 & 9 & 1.1 & 69.4 & 19 & 9.1 \\
\hline 60 & 85.6 & 84.4 & 8.8 & 1.6 & 61.6 & 23 & 11.2 \\
\hline 120 & 85.8 & 84.2 & 8.4 & 1.8 & 65.7 & 23 & 10.8 \\
\hline 180 & 100.3 & 92.9 & 9 & 0.7 & 68.3 & 24 & 12.3 \\
\hline
\end{tabular}


both n-octane and isopropanol probes (Table 6). As expected, the index of heterogeneity, $I_{\text {hete }}$, of isopropanol was much greater than that of n-octane, because the former interacted strongly with the surface functional groups through hydrogen bonds, i.e. with silanol groups, whereas the latter exchanged only non-specific interactions with the surface and was quite insensitive to the surface functionality. The indices obtained with octane or with isopropanol were quite independent of the grinding times, and their variations were erratic.

The distribution functions of the adsorption energies of n-octane and isopropanol probes on the ground attapulgite samples were considered for increasing milling times (Figure 6). For each probe used, n-octane and isopropanol, the DFAE exhibited a similar shape regardless of the milling time. Only one slightly increased tailing in the domain of the high energies, $>28 \mathrm{~kJ} /$ mole for $\mathrm{n}$-octane and $>25 \mathrm{~kJ} /$ mole for isopropanol. For isopropanol, a weak shoulder at $28 \mathrm{~kJ} /$ mole appeared progressively. Hence, the study of the evolution of the surface heterogeneity showed only a very slight change in the surface properties.

Computing the DFAE is based on a deconvolution operation, which never leads to a single solution, due to its ill-posed character. In fact, some changes in the shape of FDAE may be observed from one operator to another. In order to test the operator influence, or, in other words, to test the stability and robustness of the chosen computing method, the DFAE were computed independently by three of the co-authors. The main IGC-FC characteristic parameters of both chromatograms (irreversibility index, computed isotherm, specific surface area,
Table 6. Heterogeneity $\left(I_{\text {hete }}\right)$ index values, measured by IGC-FC for n-octane and isopropanol probes, on attapulgite samples for different grinding times.

\begin{tabular}{lcc}
\hline $\begin{array}{l}\text { Grinding time } \\
(\mathrm{min})\end{array}$ & $\begin{array}{c}I_{\text {hete }}(\mathrm{C} 8) \\
(\%) \pm 1.2\end{array}$ & $\begin{array}{c}I_{\text {hete }}(\mathrm{IP}) \\
(\%) \pm 4.9\end{array}$ \\
\hline 0 & 13.6 & 41.2 \\
30 & 14.6 & 34.5 \\
60 & 12.3 & 37.4 \\
120 & 16.1 & 38.0 \\
180 & 14.3 & 34.5 \\
\hline
\end{tabular}

BET constant, DFAE, and index of heterogeneity), obtained by the three different operators, were compared (Table 7). The most important relative standard deviations were observed for the index of heterogeneity, $\sim 10 \%$; less for the specific surface areas, $<4 \%$; and for the BET constants and irreversibility indexes with only one exception on the relative standard deviation obtained on the irreversibility index at $180 \mathrm{~min}$ of grinding time. The values confirmed the good reproducibility given by the computing method used to process the experimental chromatograms for obtaining the main IGC-FC parameters. With respect to the reproducibility of the computed DFAE, the distribution functions obtained by the three different operators were compared (Figures 7 and 8). Again no significant differences were observed between the FDRJ calculated by the three operators, either for the n-octane probe or the isopropanol probe, testifying again to the good stability of the deconvolution computing process. The slight evolutions observed for IGC-CF
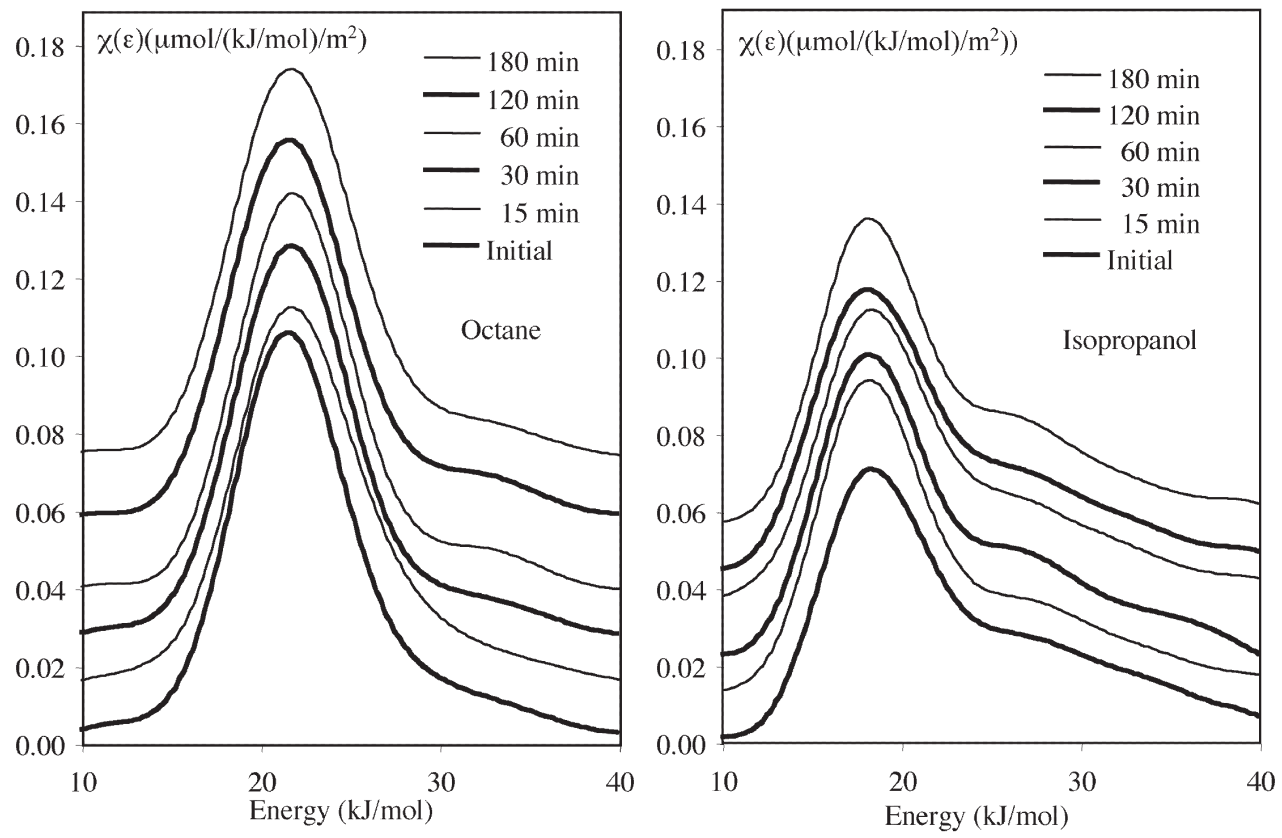

Figure 6. Distribution functions of the adsorption energies of n-octane (left) and isopropanol (right) probes measured on attapulgite samples for increasing grinding times. 
Table 7. Main IGC-FC parameters of both n-octane and isopropanol probes, computed by three different operators for two attapulgite samples, initial and after grinding for $3 \mathrm{~h}$.

\begin{tabular}{|c|c|c|c|c|c|c|c|c|c|}
\hline \multirow[b]{2}{*}{$\begin{array}{l}\text { Grinding time } \\
(\mathrm{min})\end{array}$} & \multirow[b]{2}{*}{ Operator } & \multirow[b]{2}{*}{$\begin{array}{c}S_{\mathrm{C} 8} \\
\left(\mathrm{~m}^{2} / \mathrm{g}\right)\end{array}$} & \multirow{2}{*}{$\overline{C_{\mathrm{C} 8}}$} & \multicolumn{2}{|c|}{ Octane } & \multicolumn{4}{|c|}{$\longrightarrow$ Isopropanol $\longrightarrow$} \\
\hline & & & & $\begin{array}{l}I_{\text {hete }} \\
(\%)\end{array}$ & $\begin{array}{l}I_{\mathrm{irr}} \\
(\%)\end{array}$ & $\begin{array}{c}S_{\mathrm{IP}} \\
\left(\mathrm{m}^{2} / \mathrm{g}\right)\end{array}$ & $C_{\mathrm{IP}}$ & $\begin{array}{l}I_{\text {hete }} \\
(\%)\end{array}$ & $\begin{array}{l}I_{\mathrm{irr}} \\
(\%)\end{array}$ \\
\hline & 1 & 114 & 9 & 14 & 0.6 & 71 & 22 & 41 & 8 \\
\hline \multirow[t]{2}{*}{0} & 2 & 107 & 9 & 16 & 0.6 & 69 & 22 & 49 & 8 \\
\hline & 3 & 114 & 9 & 13 & 0.6 & 73 & 21 & 41 & 8 \\
\hline \multicolumn{2}{|l|}{ Mean value } & 111.7 & 9.0 & 14.3 & 0.6 & 71.0 & 21.7 & 43.7 & 8.0 \\
\hline \multicolumn{2}{|c|}{ Relative standard deviation } & $4 \%$ & $0 \%$ & $11 \%$ & $0 \%$ & $3 \%$ & $3 \%$ & $11 \%$ & $0 \%$ \\
\hline & 1 & 93 & 9 & 15 & 0.7 & 68 & 17 & 34 & 12 \\
\hline \multirow[t]{2}{*}{180} & 2 & 92 & 9 & 12 & 0.7 & 67 & 16 & 39 & 13 \\
\hline & 3 & 94 & 9 & 14 & 0.7 & 70 & 17 & 35 & 10 \\
\hline \multicolumn{2}{|l|}{ Mean value } & 93.0 & 9.0 & 13.7 & 0.7 & 68.3 & 16.7 & 36.0 & 11.7 \\
\hline \multicolumn{2}{|c|}{ Relative standard deviation } & $1 \%$ & $0 \%$ & $11 \%$ & $0 \%$ & $2 \%$ & $3 \%$ & $7 \%$ & $13 \%$ \\
\hline
\end{tabular}

parameters and DFAE with grinding were, therefore, not significant. The IGC-FC analysis supported the fact that the grinding process did not significantly modify the surface heterogeneity of attapulgite.

\section{CONCLUSIONS}

Particle-size analysis showed that 30 min of grinding time was sufficient to reach a limiting value in particle size of $\sim 25 \mu \mathrm{m}$. During the first hour of grinding, the specific surface area measured with different probes, nitrogen, octane, and isopropanol, decreased, in accord with the disappearance of the internal structure, and the interpretation was supported by a slight decrease in the dispersive component of the surface energy determined by IGC-ID, due to the disappearance of adsorption sites. The IGC-FC method provided information on the influence of grinding on the heterogeneous character of the attapulgite surface. The advantage of IGC-FC over the other adsorption techniques, such as nitrogen adsorption, is its ability to test a solid surface with different organic probes, apolar or polar, basic or acid, in order to quantify the influence of a treatment (e.g. grinding) on the surface functionality. The modifications observed with grinding were weak from the point of view of surface heterogeneity and the interaction capacity of attapulgite, as shown by the stability of the distribution functions for both octane and isopropanol. The weak sensitivity of all the IGC measurements to grinding was shown to be related to the particular
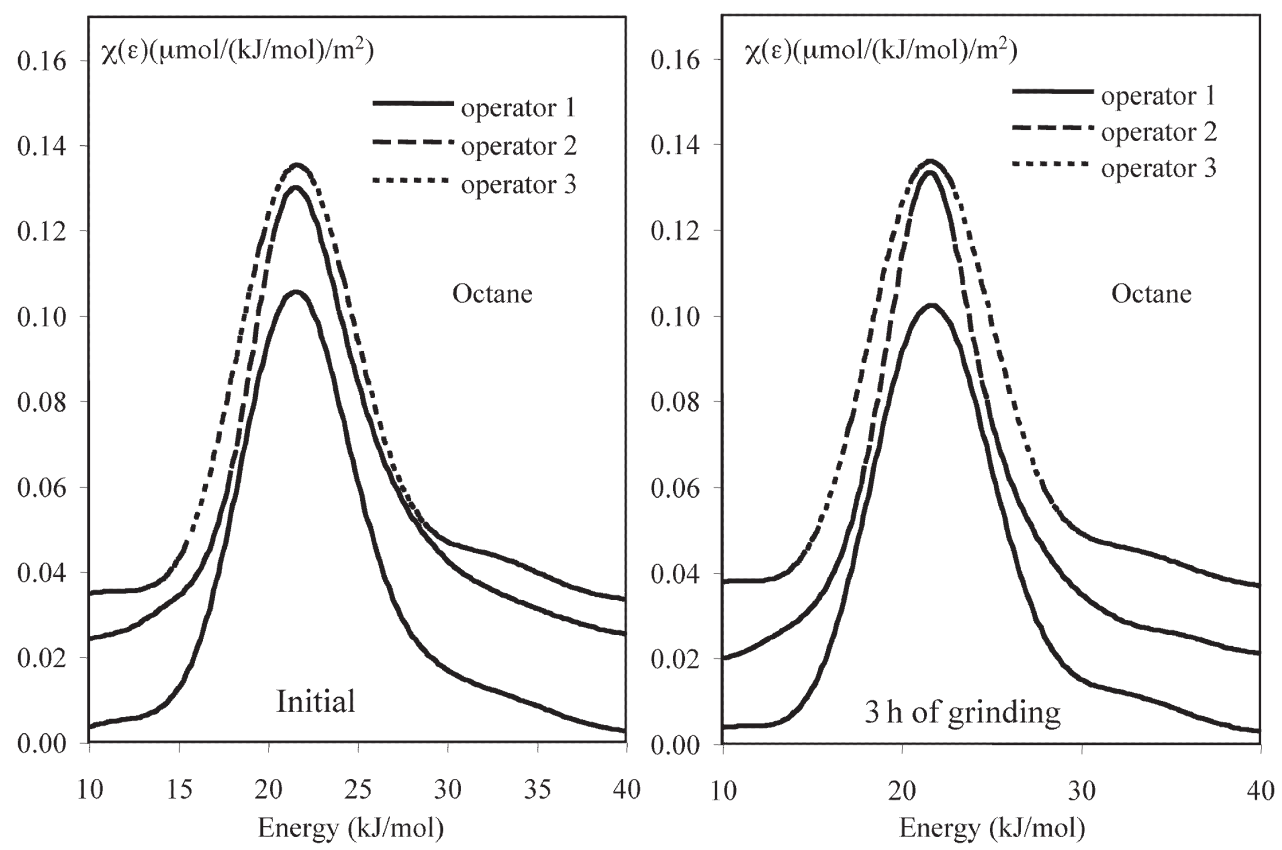

Figure 7. Distribution functions of the adsorption energies of the n-octane probe computed by three different operators for two attapulgite samples, initial (left) and after grinding for $3 \mathrm{~h}$ (right). 

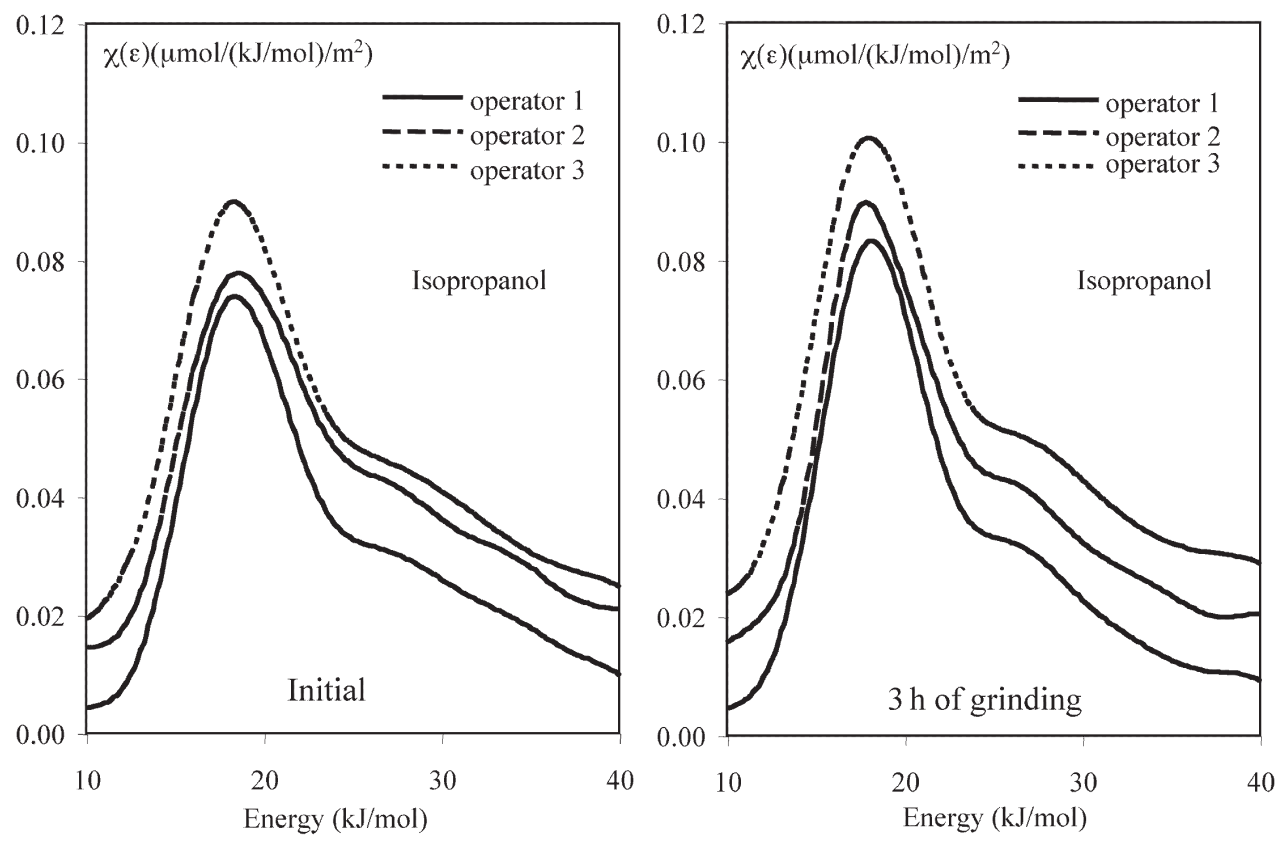

Figure 8. Distribution functions of the adsorption energies of the isopropanol probe computed by three different operators for two attapulgite samples, initial (left) and after grinding for $3 \mathrm{~h}$ (right).

structure of attapulgite clay, which is made of microporous fibers. New surfaces, resulting from the fiberbreaking process, could not contribute to modification of the surface heterogeneity.

\section{REFERENCES}

Balard, H. (1997) Estimation of the surface energetic heterogeneity of a solid by inverse gas chromatography. Langmuir, 13, 1260-1269.

Balard, H., Saada, A., Hartmann, J., Aouadj, O., and Papirer, E. (1996) Estimation of the surface energetic heterogeneity of fillers by inverse gas chromatography. Makromolekulare Symposium, 108, 63-80.

Balard, H., Aouadj, O., and Papirer, E. (1997) Monitoring, by inverse gas chromatography, of the variation of the surface energetic heterogeneity of ground muscovite samples. Langmuir, 13, 1251-1255.

Balard, H., Brendlé, E., and Papirer, E. (2000) Determination of the acid-base properties of solid surfaces using inverse gas chromatography: Advantages and limitations. Pp. 299-316 in: Acid-Base Interactions: Relevance to Adhesion Science and Technology (K. Mittal, editor). VSP, Utrecht, The Netherlands.

Balard, H., Maafa, D., Santini, A., and Donnet, J.B. (2008) Study by inverse gas chromatography of the surface properties of milled graphites. Journal of Chromatography A, 1198, 173-180.

Bradley, W.F. (1940) The structural scheme of attapulgite. American Mineralogist, 25, 405-410.

Brendlé, E. and Papirer, E. (1997) A new topological index for molecular probes used in inverse gas chromatography for the surface nanorugosity evaluation. Journal of Colloid and Interface Science, 194, 207-216.

Brendlé, E., Ozil, F., Balard, H., and Barthel, H. (2005) Adsorption of water on fumed silica. Pp. 888-894 in: Organosilicon Chemistry VI - From Molecules to Materials (N. Auner and J. Weiss, editors). Wiley, Weinheim, Germany.
Chahi, A., Petit, S., and Decarreau, A. (2002) Infrared evidence of dioctahedral-trioctahedral site occupancy in palygorskite. Clays and Clay Minerals, 50, 306-313.

Conder, J.R. and Young, C.L. (1979) Physicochemical Measurements by Gas Chromatography. Wiley Interscience, New York, pp. 385-390.

Dorris, G.M. and Gray, D.G. (1979) Adsorption, spreading pressure and London force interactions of hydrocarbons on cellulose and wood fiber surfaces. Journal of Colloid and Interface Science, 71, 93-104.

Galán, E. (1996) Properties and applications of palygorskitesepiolite clays. Clay Minerals, 31, 443-453.

Galán, E. and Carretero, I. (1999) A new approach to compositional limits for sepiolite and palygorskite. Clays and Clay Minerals, 47, 399-409.

García-Romero, E., Suarez Barrios, M., and Bustillo Revuelta, M.A. (2004) Characteristics of Aa Mg-palygorskite in Miocene rocks, Madrid Basin (Spain). Clays and Clay Minerals, 52, 484-494.

Hrachova, J., Komadel, P., and Fajnor, V.S. (2007) The effect of mechanical treatment on the structure of montmorillonite. Materials Letters, 61, 3361-3365.

Mckeown, D.A., Post, J.E., and Etz, E.S. (2002) Vibrational analysis of palygorskite and sepiolite. Clays and Clay Minerals, 50, 667-680.

Metraux, C., Grobety, B., and Ulmer, P. (2002) Filling of chrysotile nanotubes with metals. Journal of Materials Research, 17, 1129-1135.

Murray, H.H. (2000) Traditional and new applications for kaolin, smectite, and palygorskite: A general overview. Applied Clay Science, 17, 207-221.

Papirer, E., Roland, P., Nardin, M., and Balard, H. (1986) Variation of the surface energy characteristics of mica (muscovite) upon grinding. Journal of Colloid and Interface Science, 113, 62-66.

Roland, P. (1986) Contribution à l'étude du broyage des amiantes et du mica muscovite. Ph.D. thesis, Université de Haute Alsace, France, 55 pp.

Rudzinski, W., Jagiello, J., and Grillet, Y. (1982) Physical adsorption of gases on heterogeneous solid surfaces: 
evaluation of the adsorption energy distribution from adsorption isotherms and heats of adsorption. Journal of Colloid and Interface Science, 87, 478-491.

Saada, A. (1995) Origine des différences de propriétés de surface responsables des contrastes de mouillabilité des minéraux argileux des gisements pétroliers. $\mathrm{PhD}$ thesis, Université de Haute-Alsace, 1995, France, 143 pp.

Saada, A., Papirer, E., Balard, H., and Siffert, B. (1995)

Determination of the surface properties of illites and kaolinites by inverse gas chromatography. Journal of
Colloid and Interface Science, 175, 212-218.

Suarez, M. and García-Romero, E. (2006) FTIR spectroscopic study of palygorskite: influence of the composition of the octahedral sheet. Applied Clay Science, 31, 154-163.

Suraj, G., Iyer, C.S.P., Rugmini, S., and Lalithambika, M. (1997) The effect of micronization on kaolinites and their sorption behaviour. Applied Clay Science, 12, 111-130. 